\title{
Effects of Yogurt Containing Fermented Pepper Juice on the Body Fat and Cholesterol Level in High Fat and High Cholesterol Diet Fed Rat
}

\author{
Su-Jung Yeon ${ }^{1}$, Go-Eun Hong ${ }^{1}$, Chang-Kyu Kim², Woo Joon Park ${ }^{1}$, Soo-Ki Kim*, Chi-Ho Lee ${ }^{1 *}$ \\ ${ }^{1}$ Department of Food Science and Biotechnology of Animal Resources, Konkuk University, Seoul 143-701, Korea \\ ${ }^{2}$ Department of Animal Science and Biotechnology, Sangji University, Wonju 220-702, Korea \\ ${ }^{3}$ Department of Animal Science and Technology, Konkuk University, Seoul 143-701, Korea
}

\begin{abstract}
This experiment investigated whether yogurt containing fermented pepper juice (FPJY) affects cholesterol level in high fat and high cholesterol diet (HFCD) fed rat. Twenty five Sprague-Dawley male rats of 7 wk were divided into 5 groups, and fed following diets for 9 wk; CON (control diet), HFCD (HFCD), PY (HFCD supplemented with $2 \%$ of plain yogurt), LFY (HFCD supplemented with $2 \%$ of FPJY), and HFY (HFCD supplemented with $5 \%$ of FPJY). In the LFY group, hepatic total lipid level decreased significantly compared to the HFCD group $(p<0.05)$. Serum HDL cholesterol level tended to increase and hepatic total cholesterol level decreased and were comparable to the CON group ( $p>0.05$ ). In HFY group, body weight and hepatic total lipid level significantly decreased over the HFCD group $(p<0.05)$. Serum and hepatic total cholesterol level, kidney, and body fat weights decreased, and were compared to the CON group $(p>0.05)$. Liver weight decreased as FPJY content was increased. Results suggested FPJY would inhibit organ hypertrophy and accumulation of body fat, hepatic lipid, and cholesterol in HFCD fed rat.
\end{abstract}

Keywords: fermented pepper juice, yogurt, high fat and high cholesterol diet, Bacillus licheniformis, body fat accumulation

Received February 4, 2015; Revised June 4, 2015; Accepted June 4, 2015

\section{Introduction}

High cholesterol in blood can cause cardiovascular disease (Wardlaw et al., 2005), piles up and creates plaque at vessel walls, possibly leading to atherosclerosis. The blood vessel can narrow and blood circulation can be restricted so oxygen in the blood cannot reach the heart or brain, causing makes heart attacks (Wardlaw et al., 2005; Xiao et al., 2003).

Yogurt contains lactic acid bacteria. It is a probiotic food which can cause beneficial effects in the intestinal tract of humans (Odamaki et al., 2011; Tang et al., 2014). Yogurt is proven to remove cholesterol as well as decrease the serum cholesterol and low density lipoprotein (LDL) cholesterol (Akalin et al., 1997; Anderson et al.,

\footnotetext{
*Corresponding authors: Soo-Ki Kim, Department of Animal Science and Technology, Konkuk University, Seoul 143-701, Korea. Tel: +82-2-450-3728, Fax: +82-2-458-3728, E-mail: sookikim@ konkuk.ac.kr;

Chi-Ho Lee, Department of Food Science and Biotechnology of Animal Resources, Konkuk University, Seoul 143-701, Korea. Tel: +82-2-450-3681, Fax: +82-2-453-1948, E-mail: leech@ konkuk.ac.kr
}

1999; Kapila et al., 2006; Pereira et al., 2003). Therefore, yogurt can be a beneficial food for patients with cardiovascular disease.

Meanwhile, Korean pepper, especially chung-yang pepper, is famous for its pungency which results from capsaicin. Capsaicin and its several homologues are categorized as capsaicinoids. Most of the pungency results from capsaicin and dihydrocapsaicin (Iwai and Watanabe, 1999). Capsaicin inhibits body fat accumulation and promotes energy expenditure, pain relief, antibacterial activity, antioxidant activity, anti-stress activity, and inhibition of tumor cell growth (Chatteriee et al., 2010; Chen et al., 2014; Dou et al., 2011; Gerner et al., 2008; Iwai and Watanabe, 1999; Luo et al., 2011; Reinbach et al., 2009; Shin and Moritani et al., 2007). Although capsaiscin has various effects, its application in the food industry is limited because of its pungency (Kim et al., 2011).

Capsaicinoids can be degraded by several microorganisms (Cho et al., 2014; Flagan and Leadbetter, 2006; Kim et al., 2011; Lee et al., 2008). In a previous experiment, the amount of capsaicin and dihydrocapsaicin decreased as pepper was fermented by Bacillus licheniformis (Yeon et al., 2013). Fermented pepper inhibited body fat accu-

(9)This is an open access article distributed under the terms of the Creative Commons Attribution Non-Commercial License (http://creativecommons.org/licences/ by-nc/4.0) which permits unrestricted non-commercial use, distribution, and reproduction in any medium, provided the original work is properly cited. 
mulation in mice fed a high fat diet even if it lost pungency. It might have lost pungency because the food intake between the control diet fed group and the fermented pepper diet fed group showed no significant difference (Yeon et al., 2013). On the other hand, a group fed the same concentration of normal pepper diet showed significantly lowered total food intake (Yeon et al., 2013).

There is little information about the application of fermented pepper on yogurt. Yogurt is popular probiotic desert which can drink easily. It is important whether fermented pepper act as functional effect even if it is in yogurt. In this experiment, pepper juice was fermented and added to yogurt to identify the effect of degraded capsaicin in yogurt on decreasing cholesterol concentration and body fat accumulation in rats fed a high fat and high cholesterol diet (HFCD).

\section{Materials and Methods}

\section{Preparation of fermented pepper juice}

Pepper juice was extracted from chung-yang pepper that was purchased from a local market in Seoul, Korea by a juicer. This sample was mixed with bacillus minimal medium of double concentration (Bacillus minimal medium $\times 2: \mathrm{NaCl} 1 \mathrm{~g} / \mathrm{L}, \mathrm{Na}_{2} \mathrm{HPO}_{4} 9.52 \mathrm{~g} / \mathrm{L}, \mathrm{KH}_{2} \mathrm{PO}_{4} 6 \mathrm{~g} / \mathrm{L}, \mathrm{NH}_{4} \mathrm{Cl}$ $2 \mathrm{~g} / \mathrm{L}, \mathrm{MgSO}_{4} 0.48 \mathrm{~g} / \mathrm{L}, \mathrm{CaCl}_{2} 0.02 \mathrm{~g} / \mathrm{L}$, glucose $3.6 \mathrm{~g} / \mathrm{L}$ ) without glucose $(1: 1, \mathrm{v} / \mathrm{v})$. After adjustment to $\mathrm{pH} 7$, it was sterilized and 5\% of Bacillus licheniformis SK1230 was inoculated after cooling at $37^{\circ} \mathrm{C}$. It was then incubated at $37^{\circ} \mathrm{C}$ for $5 \mathrm{~d}$.

\section{Preparation of yogurts}

The composition of yogurt mix is expressed in Table 1. Milk, skim milk powder, pectin, sugar, distilled water and fermented pepper juice were mixed using a homogenizer (Homogenizer T25, Janke and Kunkel type, Germany) for $10 \mathrm{~min}$. Then, it was heated at $85^{\circ} \mathrm{C}$ for $30 \mathrm{~min}$. After cooling at $42^{\circ} \mathrm{C}$, the starter was inoculated and the mixture was incubated at $42^{\circ} \mathrm{C}$ until it reached $\mathrm{pH}$ 4.5. This yogurt was stored at $4^{\circ} \mathrm{C}$ for $24 \mathrm{~h}$ and then freeze dried to add to experimental diets. Ten milliliter of distilled water was added to the premix of plain yogurt as a substitute for fermented pepper juice. Starter (Lyofast YAB $450 \mathrm{AB}$, Sacco srl., Italy) contained Streptococcus thermophilus, Lactobacillus delbrueckii ssp. bulgaricus, Lactobacillus acidophilus and Bifidobacteriumanimalis ssp. lacti.

\section{Animal experiment}

Seven wk old 25 Sprague-Dawley male rats (Central Lab.
Table 1. The composition of yogurt premix

\begin{tabular}{ccc}
\hline \hline Ingredients & Fermented pepper juice & Plain \\
\hline Milk $(\mathrm{mL})$ & 850 & 850 \\
Skim milk powder $(\mathrm{g})$ & 40 & 40 \\
Pectin $(\mathrm{g})$ & 2 & 2 \\
Sugar $(\mathrm{g})$ & 15 & 15 \\
Distilled water $(\mathrm{mL})$ & 95 & 105 \\
Fermented pepper juice $(\mathrm{mL})$ & 10 & - \\
Starter $^{1)}(\mathrm{mg})$ & 20 & 20 \\
\hline
\end{tabular}

${ }^{1)}$ Starter: Streptococcus thermophilus, Lactobacillus delbrueckii ssp. bulgaricus, Lactobacillus acidophilus and Bifidobacteriumanimalis ssp. lacti. (Lyofast YAB 450 AB, Sacco srl., Codarago, Italy).

Table 2. The ingredients of the experimental diets

\begin{tabular}{cccccc}
\hline \hline Groups & \multirow{2}{*}{$\mathrm{CON}^{1)}$} & $\mathrm{HFCD}^{2)}$ & $\mathrm{PY}^{3)}$ & \multirow{2}{*}{$\mathrm{LFY}^{4)}$} & $\mathrm{HFY}$ ) \\
\cline { 3 - 6 } Ingredients (g) & & & & & \\
\hline Casein & 200.0 & 233.0 & 228.4 & 228.9 & 222.9 \\
Corn starch & 397.5 & 84.8 & 73.4 & 72.4 & 53.4 \\
Sucrose & 100.0 & 201.4 & 201.4 & 201.4 & 201.4 \\
Dextrose & 132.0 & 116.5 & 116.5 & 116.5 & 116.5 \\
Cellulose & 50.0 & 58.3 & 58.3 & 58.3 & 58.3 \\
Soybean oil & 70.0 & 29.1 & 25.6 & 25.8 & 20.9 \\
Lard & 0.0 & 206.9 & 206.9 & 206.9 & 206.9 \\
Mineral mixture & 35.0 & 52.4 & 52.4 & 52.4 & 52.4 \\
Vitamin mixture & 10.0 & 11.7 & 11.7 & 11.7 & 11.7 \\
L-cystine & 3.0 & 3.0 & 3.0 & 3.0 & 3.0 \\
Choline bitartrate & 2.5 & 2.5 & 2.5 & 2.5 & 2.5 \\
Cholesterol & - & 10.0 & 10.0 & 10.0 & 10.0 \\
Cholin acid & - & 5.0 & 5.0 & 5.0 & 5.0 \\
Plain yogurt & - & - & 20.0 & - & - \\
Fermented pepper yogurt & - & - & - & 20.0 & 50.0 \\
\hline Total (g) & 1000.0 & 1015.0 & 1015.0 & 1015.0 & 1015.0 \\
\hline Total (kcal) & 4000.0 & 4865.5 & 4865.5 & 4865.5 & 4865.5 \\
\hline
\end{tabular}

${ }^{1)} \mathrm{CON}$ : control diet fed group.

${ }^{2)}$ HFCD: high fat and high cholesterol diet fed group.

${ }^{3} \mathrm{PY}$ : high fat and high cholesterol diet supplemented with $2 \%$ plain yogurt powder.

${ }^{4)}$ LFY: high fat and high cholesterol diet supplemented with $2 \%$ fermented pepper juice yogurt powder.

${ }^{5)} \mathrm{HFY}$ : high fat and high cholesterol diet supplemented with 5\% fermented pepper juice yogurt powder.

Animal Inc., Korea) were individually housed in plastic cages and were acclimated for one wk. Then, animals were randomly assigned into five groups (five rats/group); the weights of each group were not significantly different $(p>$ $0.05)$. The room was maintained at $22 \pm 2^{\circ} \mathrm{C}, 50 \pm 5 \%$ humidity, and a $12 \mathrm{~h}$ light/dark cycle during the $9 \mathrm{wk}$ experimental period. The animal experiment was approved by the Institutional Animal Care and Use Committee (IACUC approval no. KU13090).

Experimental groups were as follows; CON (control diet), HFCD ( $45 \%$ kcal high fat and high cholesterol diet; HFCD), PY (HFCD supplemented with plain yogurt diet), 
LFY (HFCD supplemented with 2\% fermented pepper juice yogurt), and HFY (HFCD supplemented with 5\% fermented pepper juice yogurt). The ingredients of feed are represented in Table 2 . The feeding amount was restricted to $20.5 \mathrm{~g} /$ mouse $/ 1 \mathrm{~d}$ and tap water was available ad libitum.

The body weight was measured once a week and food intake was weighed at the same time each day using a balance (Adventurer AR2140, OHAUS crop, USA). Food intake was calculated as the difference of the feed ration of the day before and remains of the day. Feed efficiency ratio (FER) was calculated as follows; FER (\%) = body weight gain $(\mathrm{g}) /$ total food intake $(\mathrm{g}) \times 100$.

All animals had an adaptation period of $1 \mathrm{wk}$ and each experimental diet was offered to each group for $9 \mathrm{wk}$. After fasting of $24 \mathrm{~h}$, dissection was performed. Anesthesia was accomplished by diethyl ether. Blood was gathered from the abdominal vein and the spleen, liver, cecum, kidney, epididymal adipose tissue (EAT), and perirenal adipose tissue (PAT) were weighed.

\section{Serum analysis}

After standing at $25^{\circ} \mathrm{C}$ for $3 \mathrm{~h}$, serum was separated from blood and centrifuged (VS-550, Vision Scientific, Korea) at 3,000 rpm for $20 \mathrm{~min}$ at $4^{\circ} \mathrm{C}$. Serum aspartate aminotransferase (AST), total cholesterol, high density lipoprotein cholesterol (HDL cholesterol) and glucose were analyzed by Green Cross Corp. (Korea).

\section{Liver analysis}

Total lipid content was analyzed by modified Folch's method (Folch et al., 1956). The liver was homogenized with $0.85 \% \mathrm{NaCl}$, and the residue was washed with Chlo- roform/methanol $(2: 1, \mathrm{v} / \mathrm{v})$. After centrifuging at 3,000 rpm for $20 \mathrm{~min}$, the supernatant and floating matter were removed. Residue was transferred to previously weighed tube and concentrated with $\mathrm{N}_{2}$ gas. Total lipid content was calculated as concentrated tube weight minus previous weight of the tube.

Total cholesterol content was analyzed using a kit (Asan Pharm. Co., Korea). $2 \mathrm{~mL}$ of ethanol was added to the concentrated total lipid sample. Then, $20 \mu \mathrm{L}$ was mixed with $3 \mathrm{~mL}$ of enzyme solution. After storage at $37^{\circ} \mathrm{C}$ for $5 \mathrm{~min}$, absorbance was measured at $500 \mathrm{~nm}$ (Optizen 2120 UV, Mecasys Co. Ltd., Korea).

\section{Statistical analysis}

All data were expressed as mean \pm standard deviation, and analyzed by Tukey's multiple-range test using SAS ver. 8.2 software (SAS Institute, USA). Significance was declared at $p<0.05$. Extremely different value was excluded.

\section{Results and Discussion}

Body weights, food intake, and FER during the experimental period are summarized in Table 3 . Initial body weight in each group was not significantly different $(p>0.05)$. Final body weight in the HFY group significantly decreased comparing to the HFCD group $(p<0.05)$. FER in the high fat diet fed groups were significantly higher than that of the CON group $(p<0.05)$, but the HFY group showed lower FER as compared to other high fat diet fed groups $(p>0.05)$. Total food intake was same except for the HFCD group but it was not significantly lower than the other groups ( $p>0.05$ ). Kim et al. (2010) also reported lower food intake in high fat and high cholesterol diet fed groups

Table 3. Body weights and food intake for the 9 wk of experimental period

\begin{tabular}{|c|c|c|c|c|c|}
\hline Item & $\mathrm{CON}^{1)}$ & $\mathrm{HFCD}^{2)}$ & $\mathrm{PY}^{31}$ & LFY $^{4)}$ & "HFYग \\
\hline $\begin{array}{l}\text { Iinitial body weight }(\mathrm{g}) \\
\qquad(\mathrm{n}=5)\end{array}$ & $270.6 \pm 9.29^{\mathrm{NS} 7)}$ & $270.4 \pm 5.86$ & $270.4 \pm 5.86$ & $270.3 \pm 5.94$ & $270.3 \pm 5.91$ \\
\hline $\begin{array}{l}\text { Final body weight }(\mathrm{g}) \\
\qquad(\mathrm{n}=4)\end{array}$ & $477.5 \pm 6.25^{\mathrm{c}}$ & $541.5 \pm 14.27^{\mathrm{a}}$ & $536.5 \pm 2.38^{\mathrm{ab}}$ & $535.5 \pm 8.02^{\mathrm{ab}}$ & $518.8 \pm 4.35^{\mathrm{b}}$ \\
\hline $\begin{array}{l}\text { Total food intake }(\mathrm{g}) \\
\qquad(\mathrm{n}=5)\end{array}$ & $1433.0 \pm 0.00^{\mathrm{NS}}$ & $1424.2 \pm 13.42$ & $1433.0 \pm 0.00$ & $1433.0 \pm 0.00$ & $1433.0 \pm 0.00$ \\
\hline $\begin{array}{c}\mathrm{FER}^{6)}(\%) \\
(\mathrm{n}=5)\end{array}$ & $14.7 \pm 1.25^{\mathrm{b}}$ & $18.7 \pm 0.83^{\mathrm{a}}$ & $18.7 \pm 0.73^{\mathrm{a}}$ & $18.5 \pm 0.39^{\mathrm{a}}$ & $17.9 \pm 0.73^{\mathrm{a}}$ \\
\hline
\end{tabular}

\footnotetext{
${ }^{\mathrm{a}-\mathrm{c}}$ Superscripts with different letters indicate significant difference $(p<0.05)$.

${ }^{1)} \mathrm{CON}$ : control diet fed group.

${ }^{2)}$ HFCD: high fat and high cholesterol diet fed group.

${ }^{3} \mathrm{PY}$ : high fat and high cholesterol diet supplemented with $2 \%$ plain yogurt powder.

${ }^{4)}$ LFY: high fat and high cholesterol diet supplemented with $2 \%$ fermented pepper juice yogurt powder.

${ }^{5)} \mathrm{HFY}$ : high fat and high cholesterol diet supplemented with $5 \%$ fermented pepper juice yogurt powder.

${ }^{6}$ FER: food efficacy ratio.

${ }^{7)} \mathrm{NS}$ : not significant.
} 
Table 4. Weights of organs and body fats in CON, HFCD, PY, LFY, and HFY group after 9 wk of experiment

\begin{tabular}{|c|c|c|c|c|c|}
\hline Item & $\mathrm{CON}^{\mathrm{II}}$ & $\mathrm{HFCD}^{21}$ & $\mathrm{PY}^{31}$ & $\mathrm{LFY}^{4)}$ & $\mathrm{HFY}^{5}$ \\
\hline Liver $(\mathrm{g})(\mathrm{n}=5)$ & $10.4 \pm 0.32^{b}$ & $25.1 \pm 1.95^{\mathrm{a}}$ & $25.0 \pm 1.70^{\mathrm{a}}$ & $23.6 \pm 2.22^{\mathrm{a}}$ & $22.8 \pm 1.17^{\mathrm{a}}$ \\
\hline Spleen $(\mathrm{g})(\mathrm{n}=5)$ & $0.7 \pm 0.03^{\mathrm{c}}$ & $1.0 \pm 0.19^{\mathrm{ab}}$ & $1.1 \pm 0.05^{\mathrm{a}}$ & $1.0 \pm 0.13^{\mathrm{ab}}$ & $0.9 \pm 0.14^{\mathrm{b}}$ \\
\hline Kidney $(\mathrm{g})(\mathrm{n}=5)$ & $2.5 \pm 0.09^{\mathrm{b}}$ & $2.7 \pm 0.12^{\mathrm{a}}$ & $2.7 \pm 0.04^{\mathrm{ab}}$ & $2.8 \pm 0.16^{\mathrm{a}}$ & $2.6 \pm 0.18^{\mathrm{ab}}$ \\
\hline Cecum $(g)(n=5)$ & $3.1 \pm 0.49^{\mathrm{NS} 8)}$ & $3.7 \pm 0.31$ & $3.4 \pm 0.36$ & $3.3 \pm 0.23$ & $3.5 \pm 0.60$ \\
\hline $\mathrm{PAT}^{6)}(\mathrm{g})(\mathrm{n}=4)$ & $11.9 \pm 3.29^{\mathrm{b}}$ & $16.7 \pm 0.65^{\mathrm{a}}$ & $18.0 \pm 1.71^{\mathrm{a}}$ & $18.8 \pm 1.33^{\mathrm{a}}$ & $16.0 \pm 1.21^{\mathrm{ab}}$ \\
\hline $\mathrm{EAT}^{7)}(\mathrm{g})(\mathrm{n}=4)$ & $9.5 \pm 1.07^{\mathrm{b}}$ & $14.8 \pm 2.15^{\mathrm{a}}$ & $14.7 \pm 1.81^{\mathrm{a}}$ & $14.7 \pm 0.98^{\mathrm{a}}$ & $12.7 \pm 3.09^{\mathrm{ab}}$ \\
\hline
\end{tabular}

${ }^{\mathrm{a}-\mathrm{c}}$ Superscripts with different letters indicate significant difference $(p<0.05)$.

${ }^{1)} \mathrm{CON}$ : control diet fed group.

${ }^{2)}$ HFCD: high fat and high cholesterol diet fed group.

${ }^{3)} \mathrm{PY}$ : high fat and high cholesterol diet supplemented with $2 \%$ plain yogurt powder.

${ }^{4)}$ LFY: high fat and high cholesterol diet supplemented with $2 \%$ fermented pepper juice yogurt powder.

${ }^{5}$ HFY: high fat and high cholesterol diet supplemented with $5 \%$ fermented pepper juice yogurt powder.

${ }^{6}$ PAT: perirenal adipose tissue.

${ }^{7)}$ EAT: epididymal adipose tissue.

${ }^{8)} \mathrm{NS}$ : not significant.

compared to the CON group.

Weights of liver, spleen, kidney, cecum, PAT and EAT in animals are shown in Table 4. Weights of liver in high fat diet fed groups were significantly higher than CON group $(p<0.05)$ possibly because of the existence of the depot fat in liver. There were no significant differences in liver weights in high-fat diet groups, which showed decreasing tendency as fermented pepper juice concentrate in yogurt was increased $(p>0.05)$. Spleen weights in high fat diet fed groups were significantly higher than in the CON group ( $p<0.05$ ), whereas the weight of the cecum was not significantly different weight among the 5 groups $(p>0.05)$. Kidney weights in the HFCD and LFY groups were sig- nificantly higher than the CON group $(p<0.05)$. Weights of PAT and EAT in the HFCD, PY, and LFY groups were significantly higher than the CON group $(p<0.05)$, but HFY group was not $(p>0.05)$. This might bring about the significantly lower body weight in HFY group than HFCD group $(p<0.05)$. Lipid such as high body fat and cholesterols is absorbed to liver and it can cause fatty liver, moreover other hepatic diseases, which are associated with obesity (Tessari et al., 2009). HFY group showed significantly lower body fat $(p<0.05)$, therefore fermented pepper might lower occur of hepatic diseases.

Amounts of serum glucose, AST, total cholesterol, and HDL cholesterol are expressed in Table 5. Akiyama et al

Table 5. Level of serum glucose, aspartate aminotransferase, total cholesterol, HDL cholesterol in CON, HFCD, PY, LFY, and HFY group after 9 wk of experiment

\begin{tabular}{|c|c|c|c|c|c|}
\hline Item & $\overline{\mathrm{CON}^{I I}}$ & $\mathrm{HFCD}^{21}$ & 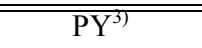 & 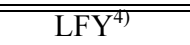 & "HFY ${ }^{5}$ \\
\hline $\begin{array}{c}\mathrm{GLU}^{6)}(\mathrm{mg} / \mathrm{dL}) \\
(\mathrm{n}=5)\end{array}$ & $78.4 \pm 11.01^{\mathrm{NS} 10)}$ & $63.8 \pm 13.48$ & $81.6 \pm 16.40$ & $72.0 \pm 5.48$ & $83.8 \pm 19.07$ \\
\hline $\begin{array}{c}\mathrm{AST}^{7)}(\mathrm{U} / \mathrm{L}) \\
(\mathrm{n}=4)\end{array}$ & $329.3 \pm 16.56^{\mathrm{b}}$ & $644.0 \pm 80.94^{\mathrm{a}}$ & $606.8 \pm 125.23^{\mathrm{a}}$ & $704.5 \pm 46.62^{\mathrm{a}}$ & $572.0 \pm 132.77^{\mathrm{a}}$ \\
\hline $\begin{array}{c}\mathrm{TC}^{8)}(\mathrm{mg} / \mathrm{dL}) \\
(\mathrm{n}=4)\end{array}$ & $70.8 \pm 2.87^{\mathrm{b}}$ & $106.5 \pm 18.12^{\mathrm{a}}$ & $113.3 \pm 11.09^{\mathrm{a}}$ & $111.5 \pm 9.98^{\mathrm{a}}$ & $88.0 \pm 16.99^{\mathrm{ab}}$ \\
\hline $\begin{array}{c}\mathrm{HDL}^{-C^{9)}}(\mathrm{mg} / \mathrm{dL}) \\
(\mathrm{n}=4)\end{array}$ & $68.0 \pm 9.20^{\mathrm{a}}$ & $51.0 \pm 4.24^{\mathrm{b}}$ & $61.0 \pm 1.15^{\mathrm{ab}}$ & $62.0 \pm 7.26^{\mathrm{ab}}$ & $54.75 \pm 4.57^{\mathrm{b}}$ \\
\hline
\end{tabular}

${ }^{\mathrm{a}, \mathrm{b}}$ Superscripts with different letters indicate significant difference $(p<0.05)$.

${ }^{1)} \mathrm{CON}$ : control diet fed group.

${ }^{2)}$ HFCD: high fat and high cholesterol diet fed group.

${ }^{3)} \mathrm{PY}$ : high fat and high cholesterol diet supplemented with $2 \%$ plain yogurt powder.

${ }^{4)}$ LFY: high fat and high cholesterol diet supplemented with $2 \%$ fermented pepper juice yogurt powder.

${ }^{5)} \mathrm{HFY}$ : high fat and high cholesterol diet supplemented with $5 \%$ fermented pepper juice yogurt powder.

${ }^{6} \mathrm{GLU}$ : glucose.

${ }^{7)}$ AST: aspartate aminotransferase.

${ }^{8)} \mathrm{TC}$ : total cholesterol.

${ }^{9)}$ HDL-C: high density lipoprotein cholesterol.

${ }^{10)} \mathrm{NS}$ : not significant. 
(1996) reported that feeding a high fat diet to rat increases serum glucose concentration even after a $24 \mathrm{~h}$ fasting for 4 wk. However, in this experiment, serum glucose content showed no significant difference $(p>0.05)$. This difference might be resulted from different strain and feeding duration (Wirth-Dzięciołowska et al., 2009). AST exist in almost all organ such as heart, liver, skeletal muscle, and kidney and it would be released to blood, if the organs are damaged (Rappaport, 1993). In this research, AST content in serum was measured, and the high fat diet fed groups were significantly higher than CON group ( $p<$ 0.05 ), maybe because of the damage from depot fat in the liver. Total cholesterol concentration in the HFY group was decreased compared to other high-fat diet groups, and it was not significantly different from the CON group ( $p>$ 0.05). According to reports of Tani et al (Tani et al., 2004) and Srinivasan and Satyanarayana (Srinivasan and Satyanarayana, 1987), total cholesterol level in capsaicin supplemented diet fed group significantly decreased $(p<0.05)$, and cholesterol excretion through fecal showed increasing tendency than control group (Tani et al., 2004). In this study, fermented product such as cleavage of capsaicin might act as a role of capsaicin in report of Tani et al. It means fast lipid metabolism in HFY group than HFCD group. HDL cholesterol amount in the HFCD group was the lowest and showed significantly lower amounts compared to that of the CON group $(p<0.05)$. On the other hand, the PY and LFY groups showed insignificant differences with the CON group ( $p>0.05)$.

Amounts of total lipid and total cholesterol in liver are represented in Table 6. The HFCD group showed the highest amount of hepatic total lipid among the 5 groups, significantly $(p<0.05)$. Level of total lipid in the PY, LFY, and HFY groups were decreased significantly compared to the HFCD group $(p<0.05)$. The PY and LFY groups showed no significant differences with the CON group $(p>0.05)$. In total cholesterol, the HFCD and PY groups were significantly higher than the $\mathrm{CON}$ group $(p<0.05)$ and the LFY and HFY groups showed decreased levels compared to the HFCD group and had no significant differences with the CON group ( $p>0.05)$. This result means that fermented pepper powder might inhibit the formation of cholesterol in liver.

Generally, absorbed capsaicin is metabolized to vanillylamine, and subsequently vanillin, vanillyl alcohol, and vanillic acid (Kawada and Iwai, 1985). These bind with transient receptor potential vanilloid 1 (TRPV1) and it secretes catecholamine and stimulates the sympathetic nerve (Iwai and Watanabe, 1999). It results in lipolysis, body heat by energy metabolism, and inhibition of body fat accumulation (Iwai and Watanabe, 1999; Iwasaki et al., 2011).

Fermentation products, such as cleavages of degraded capsaicin, in fermented pepper juice would be transferred and added to yogurt. When it is absorbed, this also would stimulate TRPV1, as capsaicin metabolites, but without pungency.

In this study, fermented pepper juice supplemented yogurt fed group showed anti-obesity, and improvement in lipid metabolism. Therefore, the final fermentation product made from fermented pepper juice might act as an inhibitor of both hypertrophy in organ and accumulation of body fat. It might effect on accumulation of hepatic lipid and high cholesterol in high fat and high cholesterol diet fed rats. Further study would be needed about the fermentation product of pepper and the identification of mechanism.

\section{Acknowledgements}

This research was supported by Technology Development Program for iPET (Korea Institute in Food, Agricul-

Table 6. Hepatic total lipid and total cholesterol amounts in CON, HFCD, PY, LFY and HFY group after 9 wk of experiment

\begin{tabular}{cccccc}
\hline \hline Item & CON $^{1)}$ & HFCD $^{2)}$ & PY $^{3)}$ & LFY $^{4)}$ & HFY $^{\text {ग) }}$ \\
\hline $\begin{array}{c}\mathrm{TL}^{6}(\mathrm{~g}) \\
(\mathrm{n}=3)\end{array}$ & $95.5 \pm 0.47^{\mathrm{c}}$ & $124.5 \pm 2.29^{\mathrm{a}}$ & $94.9 \pm 5.33^{\mathrm{c}}$ & $100.4 \pm 3.88^{\mathrm{c}}$ & $110.9 \pm 1.14^{\mathrm{b}}$ \\
$\begin{array}{c}\mathrm{TC}^{7}(\mathrm{mg} / \mathrm{dL}) \\
(\mathrm{n}=3)\end{array}$ & $43.1 \pm 9.11^{\mathrm{b}}$ & $137.5 \pm 35.96^{\mathrm{a}}$ & $122.0 \pm 45.46^{\mathrm{a}}$ & $110.2 \pm 8.55^{\mathrm{ab}}$ & $106.5 \pm 27.16^{\mathrm{ab}}$ \\
\hline
\end{tabular}

\footnotetext{
${ }^{\mathrm{a}-\mathrm{c}}$ Superscripts with different letters indicate significant difference $(p<0.05)$.

${ }^{1)} \mathrm{CON}$ : control diet fed group.

${ }^{2}$ HFCD: high fat and high cholesterol diet fed group.

${ }^{3} \mathrm{PY}$ : high fat and high cholesterol diet supplemented with $2 \%$ plain yogurt powder.

${ }^{4)}$ LFY: high fat and high cholesterol diet supplemented with $2 \%$ fermented pepper juice yogurt powder.

${ }^{5)} \mathrm{HFY}$ : high fat and high cholesterol diet supplemented with $5 \%$ fermented pepper juice yogurt powder.

${ }^{6}$ TL: total lipid.

${ }^{7)} \mathrm{TC}$ : total cholesterol.
} 
ture, Forestry and Fisheries), Republic of Korea (11304503-1-SB010).

\section{References}

1. Akalin, A. S., Gonc, S., and Duzel, S. (1997) Influence of yogurt and acidophilus yogurt on serum cholesterol levels in mice. J. Dairy Sci. 80, 2721-2725.

2. Akiyama, T., Tachibana, I., Shirohara, H., Watanabe, N., and Otsuki, M. (1996) High-fat hypercaloric diet induces obesity, glucose intolerance and hyperlipidemia in normal adult male Wistar rat. Diabetes Res. Clin. Pr. 31, 27-35.

3. Anderson, J. W. and Gilliland, S. E. (1999) Effect of fermented milk (yogurt) containing Lactobacillus acidophilus L1 on serum cholesterol in hypercholesterolemic humans. J. Am. Coll. Nutr. 18, 43-50.

4. Chatterjee, S., Asakura, M., Chowdhury, N., Neogi, S. B., Sugimoto, N., Haldar, S., Awasthi, S. P., Hinenoya, A., Aoki, S., and Yamasaki, S. (2010) Capsaicin, a potential inhibitor of cholera toxin production in Vibro cholera. FEMS Microbiol. Lett. 306, 54-60.

5. Chen, L., Hwang, J. E., Choi, B. R., Gu, K. M., Park, Y. M., and Kang, Y. H. (2014) Antioxidant capacities and cytostatic effect of Korean red pepper (Capsicum annuum L): A screening and in vitro study. J. Korean Soc. Appl. Biol. Chem. 57, 43-52.

6. Cho, S. B., Moon, H. I., Hong, G. E., Lee, C. H., Kim, J. M., and Kim, S. K. (2014) Biodegradation of capsaicin by Bacillus licheniformis SK1230. J. Korean Soc. Appl. Biol. Chem. 57, 335-339.

7. Dou, D., Ahmad, A., Yang, H. J., and Sarkar, F. H. (2011) Tumor cell growth inhibition is correlated with levels of capsaicin present in hot peppers. Nutr. Cancer 63, 272-281.

8. Flagan, S. F. and Leadbetter, J. R. (2006) Utilization of capsaicin and vanillylamine as growth substrates by Capsicum (hot pepper)-associated bacteria. Environ. Microbiol. 8, 560565 .

9. Folch, J., Lees, M., and Sloane Stanley, G. H. (1956) A simple method for the isolation and purification of total lipids from animal tissues. J. Biol. Chem. 226, 497-509.

10. Gerner, P., Binshtok, A. M., Wang, C. F., Hevelone, N. D., Bean, B. P., Woolf, C. J, and Wang, G. K. (2008) Capsaicin combined with local anesthetics preferentially prolongs sensory/nociceptive block in rat sciatic nerve. Anesthesiol. 109, 872-878.

11. Iwai, K. and Watanabe, T. (1999) Tougarashi-shinnminokagaku. Saiwaishobo, Tokyo, pp. 39.

12. Iwasaki, Y., Tamura, Y., Inayoshi, K., Narukawa, M., Kobata, K., Chiba, H., Muraki, E., Tsunoda, N., and Watanabe, T. (2011) TRPV1 agonist monoacylglycerol increases UCP1 content in brown adipose tissue and suppresses accumulation of visceral fat in mice fed a high-fat and high-sucrose diet. Biosci. Biotechnol. Biochem. 75, 904-909.

13. Kapila, S. and Vibha, P. R. S. (2006) Antioxidative and hypocholesterolemic effect of Lactobacillus casei ssp casei (bio- defensive properties of lactobacilli). Indian J. Med. Sci. 60, 361-370.

14. Kawada, T. and Iwai, K. (1985) In vivo and in vitro metabolism of dihydrocapsaicn, a pungent principle of hot pepper in rats. Agric. Biol. Chem. 49, 441-448.

15. Kim, A. R., Lee, J. J., Lee, Y. M., Jung, H. O., and Lee, M. Y. (2010) Cholesterol-lowering and anti-obesity effects of Polymnia Sonchifolia Poepp. \& Endl. powder in rats fed a high fathigh cholesterol diet. J. Korean Soc. Food Sci. Nutr. 39, 210218.

16. Kim, S. K., Cho, S. B., Kim, S. O., Won, M. Y., Lee, C. H., and Moon, H. I. (2011) Isolation of capsaicin degrading bacteria and its cleavage. Proceed. 7th Asian Pacific Conference on Clinical Nutrition. Bangkok, Thailand, pp. 1198.

17. Lee, S. M., Kim, S. Y., Lee, J. S., Yu, K. W., Chang, I. S., and Suh, H. J. (2008) Nonpungent capsicum fermentation by Bacillus subtilis and the addition of rapidase. Appl. Microbiol. Biotechnol. 81, 257-262.

18. Luo, X. J., Peng, J., and Li, Y. J. (2011) Recent advances in the study on capsaicinoids and capsinoids. Eur. J. Pharmacol. 650, $1-7$.

19. Odamaki, T., Xiao, J. Z., Yonezawa, S., Yaeshima, T., and Iwatsuki, K. (2011) Improved viability of bifidobacteria in fermented milk by cocultivation with Lactococcus lactis subspecies lactis. J. Dairy Sci. 94, 1112-1121.

20. Pereira, D. I. A., MeCartney, A. L., and Gibson, G. R. (2003) An in vitro study of the probiotic potential of a Bile-SaltHydrolyzing Lactobacillus fermentum strain, and determination of its cholesterol-lowering properties. Appl. Environ. Microb. 69, 4743-4752.

21. Rappaport, A. M. (1993) Diseases of the liver. In: Physioanatomic consideration. 7th ed, Schiff L, Schiff ER, JB Lippincott Co., Philadelphia. pp. 18-22.

22. Reinbach, H. C., Smeets, A., Martinussen, T., Moller, P., and Westerterp-Plantenga, M. S. (2009) Effects of capsaicin, green tea and $\mathrm{CH}-19$ sweet pepper on appetite and energy intake in humans in negative and positive energy balance. Clin. Nutr. 28, 260-265.

23. Shin, K. O. and Moritani, T. (2007) Alterations of autonomic nervous activity and energy metabolism by capsaicin ingestion during aerobic exercise in healthy men. J. Nutr. Sci. Vitaminol. Tokyo 53, 124-132.

24. Srinivasan, M. R. and Satyanarayana, M. N. (1987) Influence of capsaicin, curcumin and ferulic acid in rats fed high fat diets. J. Biosci. 12, 143-152.

25. Tang, Z., Ma, J., Zeng, Z., Wu, S., and Hou, M. (2014) Inhibition of atherosclerotic plaque formation in ApoE-deficient mice by dietary supplementation with Lactobacillus casei. Funct. Food Health Dis. 4, 147-158.

26. Tani, Y., Fujioka, T., Sumioka, M., Furuichi, Y., Hamada, H. and Watanabe, T. (2004) Effects of capsinoid on serum and liver lipids in hyperlipidemic rats. J. Nutr. Sci. Vitaminol. 50, 351-355.

27. Tessari, P., Coracina, A., Cosma, A., and Tiengo, A. (2009) Hepatic lipid metabolism and non-alcoholic fatty liver disease. Nutr. Metab. Cardiovas. Dis. 19, 291-302. 
28. Wardlaw, G. M., Hampl, J. S., and DiSilvestro, R. A. (2005) Perspectives in Nutrition. Lifescience, Seoul, pp. 34.

29. Wirth-Dzięciołowska, E., Karaszewska, J., Sadowski T., Pyśniak, K., and Gajewska M. (2009) Selected blood serum biochemical indicators in twelve inbred strains of laboratory mice. Anim. Sci. Pap. Rep. 27, 159-167.

30. Xiao, J. Z., Kondo, S., Takahashi, N., Miyaji, K., Oshida, K., Hiramatsu, A., Iwatsuki, K., Kokubo, S., and Hosono, A.
(2003) Effects of milk products fermented by Bifidobacterium longum on blood lipids in rats and healthy adult male volunteers. J. Dairy Sci. 86, 2452-2461.

31. Yeon, S. J., Kim, S. K., Kim, J. M., Lee, S. K., and Lee, C. H. (2013) Effect of fermented pepper powder on body fat accumulation in mice fed a high-fat diet. Biosci. Biotechnol. Biochem. 77, 2294-2297. 